\title{
The effect of bias-rearing on transfer after form discrimination training in the rat
}

\author{
YVONNE BRUINSMA and RICHARD C. TEES \\ University of British Columbia, Vancouver, British Columbia, Canada
}

\begin{abstract}
Light-, dark-, and dot-reared rats were trained on a three-way oddity discrimination of horizontal and vertical rows of dots and were then tested on five sets of transfer stimuli including the original dot stimuli and stimuli with solid stripes in the same orientations. Anomalous transfer effects and effects on discrimination ability due to biased rearing were not found to be as general as previously thought. The absence of behavioral consequence of bias-rearing is discussed in relation to recent neurophysiological and behavioral evidence.
\end{abstract}

Dramatic changes in the neurophysical properties of visual cortical neurons have been found after bias-rearing with horizontal and vertical lines (e.g., Blakemore \& Cooper, 1970; Hirsch \& Spinelli, 1971). Neurons in the visual cortices of kittens were reported to become sensitive to spots of light rather than straight-line stimuli after rearing in a planetarium-like environment (Pettigrew $\&$ Freeman, 1973). These findings seem to indicate that the development of the response specificity found in cortical units can be modified by early visual experience. The behavioral consequences of these environmental manipulations are not as clear-cut. While original reports (Blakemore \& Cooper, 1970) suggested that bias-reared kittens were blind to orientations other than the one to which they had been exposed, Muir \& Mitchell (1973) found only slight (though significant) acuity deficits in the nonexperienced orientation.

While all of these studies have involved the effect of selective exposure on the cat, there is a noticeable trend in the literature of a common mammalian response to changes in stimulation history, such as environmental deprivation or enrichment, which transcends differences among species (Tees, 1976). For example, lack of visual experience in the rat, cat, and monkey has been shown to result in retarded performance on discriminations involving complex geometric shapes, while having little effect on discriminations involving differences in line orientation and luminous flux (Riesen, 1965; Tees, 1968a, 1968b; Wilson \& Riesen, 1966).

The present study examines the consequences of biasrearing on the rat; specifically, that of a "no-line" or "dotted" environment on transfer performance after form discrimination training. Recently, a difference due to visual experience on discriminations involving contour

This investigation was supported by the National Research Council of Canada (Grant APO-179) to the second author and a NRC postgraduate scholarship to the first author. A preliminary version of this report was presented at the 1977 meeting of the Canadian Psychological Association in Vancouver, Canada. Requests for reprints should be sent to Richard C. Tees, Department of Psychology, University of British Columbia, Vancouver, British Columbia, Canada. orientation has been reported in the rat (Tees, Bruinsma, \& Midgley, in press). This study involved transfer testing with solid lines after discrimination training on single horizontal, vertical, and oblique rows of "dots" similar to those used by Dodwell $(1965,1970)$. This kind of test potentially represents a sensitive measure of the effects of early selective exposure to a planetarium-like environment. A three-way oddity paradigm was employed in discrimination training in an attempt to emphasize the perceptual rather than memorial processes underlying such discrimination tasks (Over, 1967).

\section{METHOD}

\section{Subjects and Rearing Conditions}

A total of 40 male and 40 female Long-Evans hooded rats (Rattus norvegicus) from 15 litters were randomly assigned to one of four rearing conditions: light-reared (LR), dark-reared (DR), dot-reared (Dot-R), and dark-stress (DR-S). Subjects were assigned so that a maximum of three subjects per cell came from the same litter.

The general rearing conditions for DR and $L R$ rats have been described previously (Tees, 1968b). Subjects were born in plastic cages $(42 \times 15 \times 24 \mathrm{~cm})$ and at 25 days of age were weaned and transferred into like-sex group cages $(63.4 \times 17.8 \times 25.5 \mathrm{~cm})$. After 60 days of age, they were housed in individual cages $(17.8 \times 17.8 \times 25.5 \mathrm{~cm})$. The LR rats were housed in a room maintained on a 12-h-light/12-h-dark schedule. For the remaining three groups, litters were transferred to a dark room on the day of birth and were housed there for the entire experiment. All subjects were handled for a short period daily for 5 days before training began.

The Dot- $R$ rats received restricted visual stimulation from the age of 15 to 45 days. This consisted of placement in individual cylinders $(21 \times 7.5 \mathrm{~cm})$ for $2 \mathrm{~h}$ daily. Except for light entering the cylinders through a random array of pinholes on one end of the tube, the apparatus was light-tight. The 20 pinholes were scattered over an area $5 \mathrm{~cm}$ in diam and were a minimum of $4 \mathrm{~mm}$ apart. This amounted to a visual angle of $3.5 \mathrm{deg}$ at the expected viewing distance and insured that no two dots fell within the typical receptive field of a single cortical neuron (Weisenfeld \& Kornel, 1975). Since the dot-rearing procedure involved a considerable amount of handling and possible stress due to isolation and confinement, a DR-S group was run. The DR-S rats received the same handling as the Dot-R rats but did not receive any visual stimulation. 


\section{Apparatus}

Training and testing took place in a shock-avoidance apparatus with three stimulus doors similar to that described by Tees (1968a). It consisted of a startbox, a choice chamber, and a goalbox. Two translucent (detachable) swinging doors $(8.5 \mathrm{x}$ $8.5 \mathrm{~cm})$ and a center translucent guillotine door $(8.5 \times 7.0 \mathrm{~cm})$ appeared at the end of the choice chamber. The three doors to the goalbox were separated by two vertical partitions that extended $10.2 \mathrm{~cm}$ into the choice chamber. The grid floor in the choice chamber was wired independently of the grid section below the doors and the grid in the startbox. The doors were illuminated by three $75-\mathrm{W}$ bulbs behind a translucent panel at the back of the goalbox.

\section{Training and Transfer Test Procedure}

Training stimuli were horizontal and vertical arrays of roughly circular dots (see Figure 1). Each dot was $.5 \mathrm{~cm}$ in diam. The between-to-within column distance ratio was $2.5: 1$. Transfer stimuli included the original dot arrays as well as stripes $(.5 \mathrm{x}$ $6.5 \mathrm{~cm}$ ) in the same orientations. The dot and stripe stimuli appeared as white through the translucent Plexiglas door, which was illuminated from behind. The remainder of each door was covered with black tape. The luminance of each dot stimulus target was maintained at 1.2 candles $/ \mathrm{m}^{2}$ and the solid striped stimuli involved in transfer testing at 5.0 candles $/ \mathrm{m}^{2}$.

Training began at 90 days of age and took place in a dark, quiet room. Following 4 days of pretraining with blank doors in the test apparatus (described previously, Tees, 1968b), the stimulus doors were inserted and all subjects were trained on the horizontal-vertical dot array discrimination. Half of the subjects were trained to respond positively to the horizontal stimulus and half to the vertical stimulus. The rats could enter the goalbox through the positive door but received a mild footshock when they came within $10 \mathrm{~cm}$ of the locked negative door. The stimulus in the center position was always negative, so that the rats had to choose between one positive and two negative doors. The center door did not open to the goalbox. The position of the positive and negative lateral doors in the apparatus varied according to a prearranged Gellerman sequence. Subjects received 10 trials daily until the criterion of $90 \%$ correct responses over 2 consecutive days was obtained.

Upon reaching criterion on the original discrimination, all subjects underwent 5 days of transfer testing (see Figure 1). Each day they received 10 transfer trials alternating with 10 trials with the original stimuli. All subjects received the transfer tests in the same order. On Days 1 and 2 , both stimuli were in the same positive or negative orientation and the rats had to discriminate on the basis of dots vs. solid stripes. On the last 3 days, the rats could make the discrimination on the basis of the orientation cue.

\section{RESULTS}

The number of trials to criterion and the standard deviations for the four rearing conditions are presented
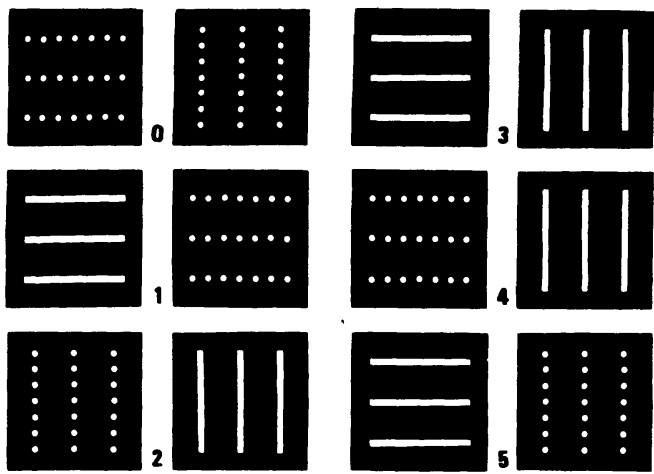

Figure 1. Training and transfer test stimuli for the horizontalpositive group. The left one of each pair was positive. The vertical-positive group was trained and tested on a corresponding set of stimuli.

in Table 1. It took an average of 165 trials for the rats to reach criterion on the original discrimination. There were no statistically significant differences due to rearing, gender, or positive stimulus on this measure.

On Transfer Tests 1 and 2, the average scores were 4.90 and 5.76 out of 10 , respectively. A separate analysis of variance was done for each transfer test. Differences due to rearing, sex, or positive stimulus were not significant. However, combining the groups on the basis of presence or absence of visual experience or stress did result in significant differences on multiple $t$ ratios (Kirk, 1968). On Transfer Test 1, the stressed groups, Dot-R and DR-S, scored lower (mean $=4.5)$ than the nonstressed (mean $=5.3) \mathrm{LR}$ and DR rats $(\mathrm{t}=2.36$, $\mathrm{df}=64, \mathrm{p}<.05)$. On Transfer Test 2 , the rats which received early visual stimulation, LR and Dot-R, scored higher (mean $=6.2$ ) than the two visually inexperienced $($ mean $=5.4)$ DR and DR-S groups $(t=2.29, \mathrm{df}=64$, $\mathrm{p}<.05)$.

On the remaining three transfer tests, all subjects transferred well and scored above 8 out of 10. Orientation is clearly a powerful cue for all of the rats. There was a significant difference due to rearing on each of these tests $(F=3.89-7.85, \mathrm{df}=3, \mathrm{p}<.05)$. The DR-S groups scored consistently lower than the other three groups.

The scores on the interspaced trials with the original stimuli over the 5 days of testing averaged 9 out of 10 except on Day 2, when the scores fell to 7.3 out of 10

Table 1

Acquisition and Transfer Test Scores

\begin{tabular}{|c|c|c|c|c|c|c|c|c|}
\hline \multirow[b]{3}{*}{ Rearing } & \multicolumn{3}{|c|}{ Discrimination } & \multicolumn{5}{|c|}{ Transfer* } \\
\hline & \multicolumn{3}{|c|}{ Trials to Criterion } & \multirow{2}{*}{$\frac{\begin{array}{c}1 \\
\text { PS and PD }\end{array}}{\text { Mean }}$} & \multirow{2}{*}{$\begin{array}{c}2 \\
\text { NS and ND } \\
\text { Mean } \\
\end{array}$} & \multirow{2}{*}{$\begin{array}{c}3 \\
\text { PS and NS } \\
\text { Mean }\end{array}$} & \multirow{2}{*}{$\begin{array}{c}4 \\
\text { PD and NS } \\
\text { Mean }\end{array}$} & \multirow{2}{*}{$\begin{array}{c}5 \\
\text { PS and ND } \\
\frac{\text { Mean }}{}\end{array}$} \\
\hline & $\mathrm{N}$ & Mean & SD & & & & & \\
\hline Dot-R & 20 & 156.5 & 32.8 & 4.55 & 6.25 & 8.55 & 9.20 & 9.05 \\
\hline DR & 20 & 173.0 & 46.2 & 5.30 & 5.65 & 9.25 & 9.45 & 9.60 \\
\hline DR-S & 20 & 172.0 & 38.1 & 4.45 & 5.10 & 8.30 & 8.20 & 8.40 \\
\hline LR & 20 & 157.0 & 55.6 & 5.30 & 6.05 & 9.60 & 9.70 & 9.70 \\
\hline
\end{tabular}

NOTE-PS = positive-stripe, $N S=$ negative-stripe, $P D=$ positive-dot,$N D=$ negative-dot .

${ }^{*}$ Score is number of responses out of 10 to the first of the two stimuli. 
for all of the rearing conditions. Overall, there were no significant differences due to rearing condition on these trials.

\section{DISCUSSION}

The results of this experiment provide little evidence of anomalous transfer as described by Dodwell $(1965,1970)$. This replicates similar findings by Tees (1975) and Tees et al. (in press). One of the differences between studies in our laboratory and those of Dodwell is that we used a shock-avoidance situation, whereas Dodwell's rats were trained on food reinforcement. Whether this potential difference in motivation is the factor which limits the generality of anomalous transfer effects remains to be determined.

The effect of visual experience on transfer after form discrimination training is not clear-cut. The visually experienced and inexperienced groups differed only on Transfer Test 2 . The previously mentioned study by Tees et al. (in press) showed a difference due to rearing on transfer tests similar to those employed in the present study as the first and second transfer test series. The stimuli they used were single rows of dots and stripes. It may be that the stimuli with the three stripes and three rows of dots attenuated any differences between groups rather than amplifying them, as was hoped.

Strong conclusions regarding the effect of dot-rearing cannot be made from the results of this experiment. The absence of significant behavioral differences between the rearing conditions is consistent with the suggestion of Blasdel, Mitchell, Muir, and Pettigrew (1977) that, although neurophysiological deficits are pronounced immediately after restricted visual stimulation, these differences attenuate as the length of time between original stimulation and testing is increased. Our rats did not receive any visual stimulation between 45 and 90 days of age. It is possible that behavioral effects of bias-rearing may have been present at 45 days, immediately after rearing, but not at 90 days, when testing began. Another possibility is that the behavioral consequences simply are not as se ious as neurophysiological evidence would suggest. Whether this is related to the nature of behavioral testing or single-unit recording or the relationship between single-unit characteristics and perceptual abilities is not clear, but the findings of the present study are consistent with reports of minor deficits found in bias-reared cats (e.g., Muir \& Mitchell, 1973). The effectiveness of our bias-rearing procedure in producing neurophysiological changes in the visual cortex was not determined, but there is no reason to believe that if these neurons are modified by bias-rearing, they would not be affected by the particular restriction employed in this experiment. The effects of visual deprivation and enrichment on the anatomy and physiology of the rat's visual system are found to be very similar to those for other species (Greenough, 1976; Shaw, Yinon, \& Auerbach, 1975).

The advantage of using the three-way oddity vs. a two-way discrimination paradigm is also not clear. Preliminary data indicate that reversing which transfer stimulus is the odd one in the set does not alter the results. This is in agreement with a previous report (Tee \& Riesen, 1974) that, on discriminations involving more potent cues, "oddity" is not attended to and may in fact complicate the learning of the discrimination.

In summary, then, the results suggest that the anomalous transfer and the differences due to visual experience on transfer after form discrimination training are not as general as previously thought. Although the results are confounded by factors other than visual experience (resulting from the rearing procedure), the complex stimuli used, and the oddity paradigm, it seems quite probable that the behavioral consequences of dotrearing are not very dramatic.

\section{REFERENCES}

Blakemore. C.. \& Cooper, G. F. Development of the brain depends on the visual environment. Nature, 1970, 228, 477-478.

Blasdel. G. G.. Mitchell, D. E., Muir, D. W., \& Pettigrew. J. D. A physiolcgical and behavioral study in cats of the effect of early visual experience with contours of a single orientation. Journal of Physiology, 1977, 265. 615-636.

Dodwell. P. C. Anomalous transfer effects after shape discrimination training in the rat. Psychonomic Science, 1965, 3. 97.98.

Dodwell. P. C. Anomalous transfer effects after shape discrimination training in rats and squirrels. Journal of Comparative and Phy'siological Psychology, 1970, 71, 42-51.

Greenough. W. T. Enduring brain eifects of differential experience and training. In M. R. Rosenzweig \& E. L. Barnett (Eds.). Neural mechanisms of learning and memory. Cambridge. Mass: MIT Press, 1976.

HiRsch. H. V. B.. \& Spinelli, D. N. Modification of receptive field orientation in cats by selective visual exposure during development. Experimental Brain Research, 1971. 12, 509-527.

KIRK. R. E. Experimental design: Procedures for the behavioral sciences. Belmont, Calif: Wadsworth, 1968.

Muir. D. W., \& Mitchell, D. E. Visual resolution and experience: Acuity deficits in cats following early selective visual deprivation. Science, 1973, 180, 420-422.

OVER. R. Detection and recognition measures of shape discrimination. Nature. 1967, 214, 1272-1273.

Pettigrew, J. D.. \& Freeman, R. D. Visual experience without lines: Effect on developing cortical neurons. Science, 1973. 182. 599-601.

RIESEN, A. H. Effects of visual deprivation on perceptual function and neural substrate. In J. Ajuriaguerra (Ed.), Deafferentation experimentale et clinique. Geneva: George, 1965.

Shaw. C.. Yinon, U., \& Auerbach, E. Receptive fields and response properties of neurons in the rat visual cortex. Vision Research, 1975, 15, 203-208.

TEE. K. S.. \& RiEsen, A. H. Visual right-left confusions in animals and man. In G. Newton \& A. H. Riesen (Eds.), Advances in psychobiology (Vol. 2). New York: Wiley, 1974.

TEES, R. C. Effects of early restriction on later form discrimination in the rat. Canadian Journal of Psychology, 1968, 22. 294-298. (a)

TEES, R. C. Effect of early visual restriction on later visual identity discrimination in rats. Journal of Comparative and Physiological Psychology, 1968, 66, 224-227. (b)

TEEs, R. C. The effects of neonatal striate lesions and visual experience on form discrimination in the rat. Canadian Journal of Psychology. 1975, 29, 66-85.

TEES. R. C. The study of mammalian perceptual development using controlled rearing. In G. Gottlieb (Ed.), Studies on the development of behavior and the nervous system (Vol. 3). New York: Academic Press, 1976.

Tees, R. C., Bruinsma, Y., \& Midgley, G. The effects of visual deprivation in the rat on transfer effects after form discrimination training. Developmental Psychobiology, in press.

Wiesenfeld, Z., \& Kornell, E. E. Receptive fields of single cells in the visual cortex of the hooded rat. Brain Research. 1975, 94. 401-412.

Wilson, P. D., \& RiEsen, A. H. Visual development in rhesus monkeys neonatally deprived of patterned light. Journal of Comparative and Physiological Psychology, 1966, 61, 87-95.

(Received for publication August 1, 1977.) 